\title{
THE POTENTIAL OF THE SYNERGY OF SUNPHOTOMETER AND LIDAR DATA TO VALIDATE VERTICAL PROFILES OF THE AEROSOL MASS CONCENTRATION ESTIMATED BY AN AIR QUALITY MODEL
}

\author{
N. Siomos $^{1 *}$, M. Filioglou ${ }^{1,2}$, A. Poupkou ${ }^{1}$, N. Liora ${ }^{1}$, S. Dimopoulos ${ }^{1}$, D. Melas ${ }^{1}$, \\ A. Chaikovsky ${ }^{3}$ and D. S. Balis 1 \\ ${ }^{1}$ Laboratory of atmospheric physics, Physics Department, Aristotle University of Thessaloniki, \\ Greece \\ ${ }^{2}$ Finnish Meteorological Institute, Kuopio Unit, Finland \\ ${ }^{3}$ Institute of Physics, National Academy of Science, Minsk, Belarus \\ *Email: nsiomos@physics.auth.gr
}

\begin{abstract}
Vertical profiles of the aerosol mass concentration derived by the Lidar/Radiometer Inversion Code (LIRIC), that uses combined sunphotometer and lidar data, were used in order to validate the aerosol mass concentration profiles estimated by the air quality model CAMx. Lidar and CIMEL measurements performed at the Laboratory of Atmospheric Physics of the Aristotle University of Thessaloniki, Greece $(40.5 \mathrm{~N}, 22.9 \mathrm{E})$ from the period $2013-2014$ were used in this study.
\end{abstract}

\section{ALGORITHMS AND MODELS}

CAMx is an air quality model (ENVIRON, 2010) that can provide, among others, the vertical mass concentration profiles of PM2.5 and PM10 aerosol. Input data include meteorological fields from the WRF model, natural and anthropogenic emission data, landuse and photochemistry data. Natural emissions include windblown dust from soils, sea salt aerosol and vegetation non-methane volatile organic compounds (NMVOCs) formating secondary organic aerosols (SOA), while anthropogenic emissions include fossil fuel burning procedures like heating, industry, transportation and energy production at power plants. Waste treatment and disposal, agricultural activities like biomass burning and fertilization and extraction and distribution of fossil fuels and geothermal energy are also considered. It is important to mention that the emissions due to dust resuspension during agricultural activities and road traffic as well as the Saharan dust emissions are not currently included. Saharan dust emissions are taken into account only indirectly from the model's chemical boundary conditions taken from the chemistry transport model IFSMOZART. A nesting technique is being used to increase accuracy near the area of interest and thus the spatial resolution is $30 \times 30 \mathrm{~km}$ in the European domain, $10 \times 10 \mathrm{~km}$ in the East Mediterranean domain and $2 \times 2 \mathrm{~km}$ around Athens and Thessaloniki. More on the simulations of CAMx for Thessaloniki can be found in Poupkou et al., 2012.

LIRIC algorithm utilizes both sunphotometer data that have been processed by AERONET algorithms and elastic backscatter lidar data at three wavelengths $(355 \mathrm{~nm}, 532 \mathrm{~nm}$ and $1064 \mathrm{~nm})$ in order to estimate the aerosol concentration profiles for fine and coarse particles. The algorithmic inversion is described in detail in Chaikovski et al. 2012.

\section{METHODOLOGY}

The aerosol mass concentration profiles of the fine and coarse mode derived by CAMx were compared with the respective profiles derived by the retrieval algorithm. For the coarse mode particles, forecasts of the Saharan dust transportation model BSC-DREAM8bV2 were also taken into account. Each of the retrieval algorithm's profiles was matched to the models' profile with the best agreement within a time window of four hours before and after the central measurement. Since LIRIC derived profiles are in 
ppb units it was necessary to convert them in $\mu \mathrm{gr} / \mathrm{m}^{3}$ in order to compare them with the models' profiles (see e.g. Kokkalis et al., 2013). We assumed a mean density of $1.5 \mu \mathrm{gr} / \mathrm{m}^{3}$ for the fine mode and $2.6 \mu \mathrm{gr} / \mathrm{m}^{3}$ for the coarse mode. These values are typical for the fine and coarse mode particles respectively (see e.g. Kokkalis et al., 2013).

Mean concentration profiles of CAMx and LIRIC were derived for both modes. For the calculation of the mean bias error, the root mean square error and the temporal correlation coefficient it was necessary to interpolate LIRIC and CAMx profiles to the same vertical resolution.

Optical Properties of Aerosols and Clouds (OPAC), a software that can provide optical properties of aerosol mixtures [Hess et al., 1998], was also employed in order to calculate the Angstrom exponent values for $355 \mathrm{~nm} / 532 \mathrm{~nm}$ and $532 \mathrm{~nm} / 1064 \mathrm{~nm}$ for each of the model's profiles, aiming for a comparison with the Angstrom exponent values derived by the retrieval algorithm for each measurement.

\section{RESULTS}

The mean concentration profiles for the fine mode particles and the respective mean bias error are presented below.

The comparison of the aerosol fine mode concentration profiles presented in Figure 1 shows good agreement between CAMx and the retrieval algorithm, especially above $1.5 \mathrm{~km}$. The mean bias error shown in Figure 2, is slightly above $5 \mu \mathrm{gr} / \mathrm{m}^{3}$ below $1 \mathrm{~km}$ and ranges between $0-5 \mu \mathrm{gr} / \mathrm{m}^{3}$ in the layer between 1 and $5 \mathrm{~km}$. Only nine cases were included since the data availability of concurrent Lidar and CIMEL measurements and CAMx forecasts was low.

As far as the aerosol coarse mode concentration profiles is considered, both CAMx and BSC-DREAM8bV2 values are severely underestimated (not shown here), although, in cases of Saharan dust transportation events there is an agreement between the profiles of BSCDREAM8bV2 model and the retrieval algorithm. A typical case is presented in Figure 3.

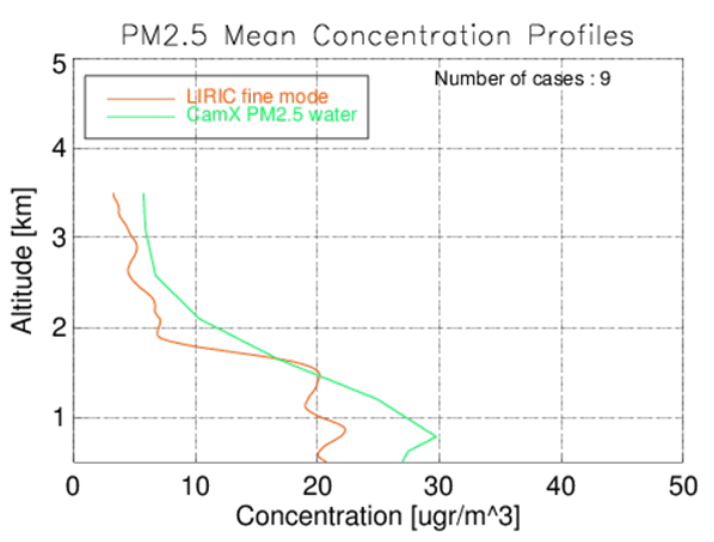

Figure 1. Comparison of the mean concentration profiles derived by CAMx and LIRIC for the fine mode particles.

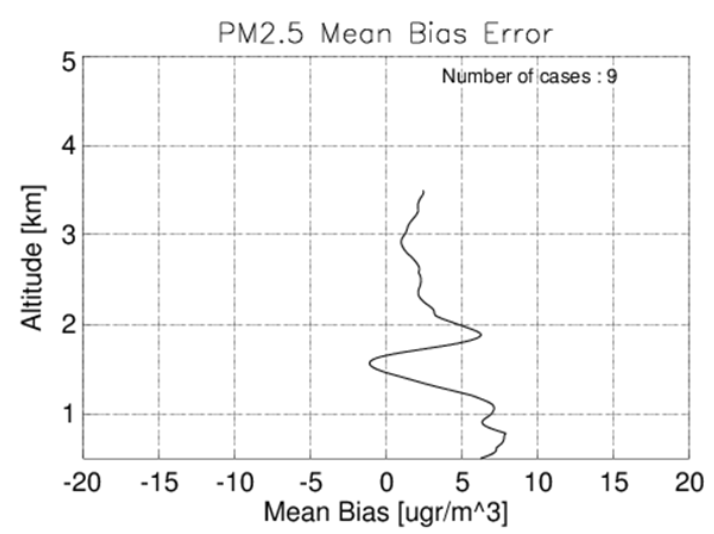

Figure 2. Mean bias error profile between CAMx and LIRIC for the fine mode particles.

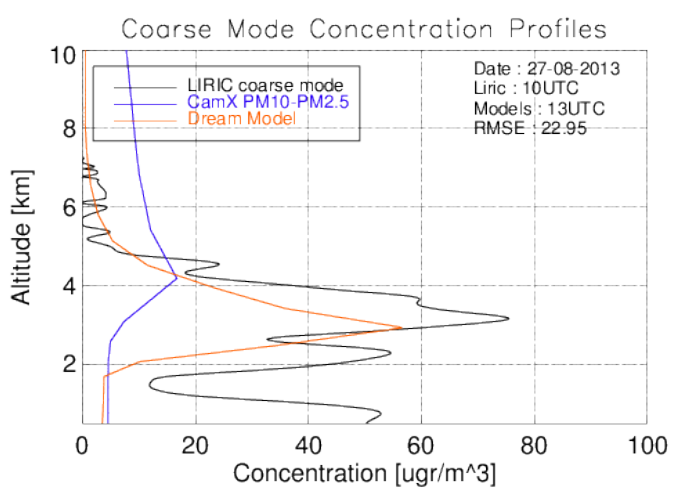

Figure 3. Comparison of the aerosol coarse mode concentration profiles between LIRIC [black], CAMx [blue] and BSC-DREAM8bV2 [red]. 
The aerosol Angstrom exponent comparison resulted in an underestimation of the values derived by OPAC for both $355 \mathrm{~nm}-532 \mathrm{~nm}$ and $532 \mathrm{~nm}-1064 \mathrm{~nm}$ spectral regions. The scatterplots of OPAC and LIRIC derived Angstrom exponent values are presented in Figures 4 and 5.

There is some linear behavior in both graphs. The Pearson correlation coefficient is 0.49 in the $355 \mathrm{~nm}-532 \mathrm{~nm}$ region and 0.60 in the $532 \mathrm{~nm}-$ $1064 \mathrm{~nm}$ region. There are indications that CAMx is underestimating the sea salt emission. Greater sea salt values could lead to OPAC calculating smaller Angstrom values since sea salt consist mainly of coarse mode particles.

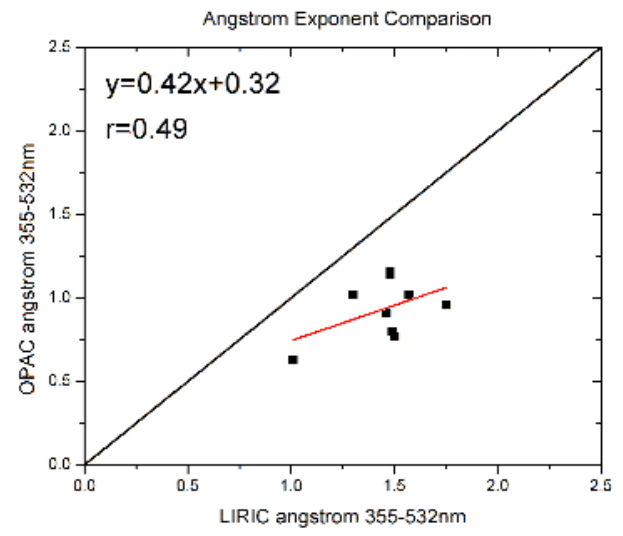

Figure 4. Scatterplot of the Aerosol Angstrom Exponent $355 \mathrm{~nm}-532 \mathrm{~nm}$ derived by LIRIC and OPAC.

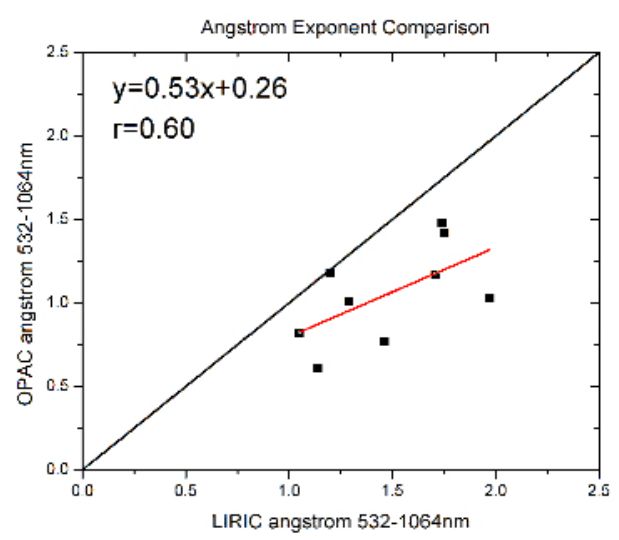

Figure 5. Scatterplot of the Aerosol Angstrom Exponent 532nm-1064nm derived by LIRIC and OPAC.

\section{CONCLUSIONS}

The comparison of the aerosol fine mode concentration profiles resulted in a good agreement between the model and the retrieval estimates, with the vertical mean bias mostly ranging between 0 and $5 \mu \mathrm{gr} / \mathrm{m}^{3}$. As far as the aerosol coarse mode concentration profiles is considered, CAMx severely underestimates the aerosol concentration This probably occurs because aerosol emission sources outside the domain of CAMx, like Sahara desert, are not directly included in the model's emissions. In addition emissions from local dust sources are underestimated in CAMx. In cases of Saharan dust transport events there is a reasonable agreement between BSC-DREAM8bV2 model and the retrieval algorithm. The aerosol Angstrom exponent comparison resulted in an underestimation of the values derived by OPAC for both $355-532 \mathrm{~nm}$ and $532-1064 \mathrm{~nm}$ spectral regions, showing however a significant correlation of 0.5 to 0.6

\section{FUTURE PLANS}

Processing and comparison of additional cases in order to produce more accurate results is under progress. Furthermore the validation with a new run of CAMx is planned, which will use updated emission inventories.

\section{ACKNOWLEDGEMENT}

The financial support by the European Commission through ACTRIS project (EU INFRA-2010-1.1.16-262254) is gratefully acknowledged. CIMEL Calibration was performed at the AERONET-EUROPE calibration center, supported by ACTRIS (European Union Seventh Framework Program; FP7/2007-2013) under grant agreement no. 262254.

The IFS-MOZART simulations were performed in the framework of the MACC-III project (Monitoring Atmospheric Composition and Climate -III), Horizon 2020, under grant agreement no: 633080 


\section{REFERENCES}

Chaikovski, A., Dubovik, O., Pappalardo, G., Wandinger, U., Apituley, A., Alados Arbroledas, L., Pappayannis, A., Pietruczuk, A. (2012), Algorithm and Software for the retrieval of Vertical Aerosol Properties using combined Lidar/Radiometer data : Dissemination in EARLINET, Reviewed and Revised Papers of the $26^{\text {th }}$ International Laser Radar Conference, Porto Helli, Greece

ENVIRON International Corporation (2010), CAMx - User's Guide - Comprehensive Air Quality Model with Extensions Version 5.30, Novato, California

Hess, M. and Koepke, P. and Schult, I. (1998), Optical Properties of Aerosols and Clouds: The Software Package OPAC, American Meteorological Society

Kokkalis P., A. Papayannis, V. Amiridis, R. E. Mamouri, I. Veselovskii, A. Kolgotin, G. Tsaknakis, N. I. Kristiansen, A. Stohl5, and L. Mona (2013): Optical, microphysical, mass and geometrical properties of aged 72 volcanic particles observed over Athens, Greece, during the Eyjafjallajökull eruption in April 2010through synergy of Raman Lidar and sunphotometer measurements, Atmos. Chem. Phys., 13, 9303-9320, 2013.

Poupkou, A., Markakis, K., Liora, N., Giannaros, T. and Melas, D., 2012. "Particulate matter source apportionment for the urban center of Thessaloniki (Greece) using the WRF-CAMx modeling system". 19th International Transport and Air Pollution Conference 2012, 26-27 November 2012, Thessaloniki, Greece. 